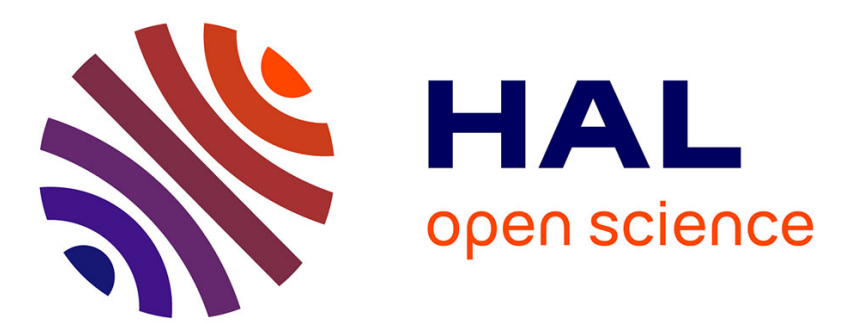

\title{
Correlation between the oxygen content and the morphology of AlN films grown by r.f. magnetron sputtering Valerie Brien, P Pigeat
}

\section{- To cite this version:}

Valerie Brien, P Pigeat. Correlation between the oxygen content and the morphology of AlN films grown by r.f. magnetron sputtering . Journal of Crystal Growth, 2008. hal-01396547

\section{HAL Id: hal-01396547 \\ https://hal.science/hal-01396547}

Submitted on 14 Nov 2016

HAL is a multi-disciplinary open access archive for the deposit and dissemination of scientific research documents, whether they are published or not. The documents may come from teaching and research institutions in France or abroad, or from public or private research centers.
L'archive ouverte pluridisciplinaire HAL, est destinée au dépôt et à la diffusion de documents scientifiques de niveau recherche, publiés ou non, émanant des établissements d'enseignement et de recherche français ou étrangers, des laboratoires publics ou privés. 


\title{
Publié dans Journal of Crystal Growth 310 (2008) 3890- 3895
}

Correlation between the oxygen content and the morphology

of AlN films grown by r.f. magnetron sputtering

\author{
V. Brien*, P. Pigeat \\ CNRS/Nancy-University (LPMIA UMR CNRS 7040) \\ Boulevard des Aiguillettes B.P. 239 \\ F-54506 Vandœuvre lès Nancy, France
}

* Corresponding author, E-mail address: valerie.brien@ univ-lorraine.fr, Tel.: + 33 (0) 83 6849 28, Fax: + 33 (0) 383684933

\begin{abstract}
To understand the influence of the oxygen on the crystallography of AlN thin films made by physical vapour deposition r.f. magnetron, three different oxygen contents AlN films were prepared at room temperature for two values of the energy of the species building the film (low energy obtained by using : low power W, high pressure P; high energy obtained by using : high $\mathrm{W}$, low $\mathrm{P})$. It is observed that the crystalline morphology of the films not only depends on the process parameters ( $\mathrm{W}$ and $\mathrm{P}$ ), but is also particularly related to the oxygen content in the films. Regardless of $\mathrm{P}$ and $\mathrm{W}$ used here, low oxygen contents films (5 atomic \%) are columnar. The increase in oxygen content (15 to 30 atomic \%) reduces the grain size without creating phases like $\mathrm{Al}_{2} \mathrm{O}_{3}$ or AlNO. And very rich oxygen films (50 atomic \%) are amorphous. From this study assumptions are made for the localization of oxygen atoms in the AlN phase.
\end{abstract}

Keywords: A1. Crystal morphology, Defects, A3. Physical vapor deposition processes, B1. Nitrides, B2. Semiconducting III-V materials 


\section{PACS classification codes: 81.10.Aj, 81.15.Cd, 73.61.Ey, 68.55.-a}

\section{Introduction}

In recent years, there has been large interest in near-nano and nano-structured materials [1]. Quantum confinement promotes the nano-sized materials to exhibit unusual and unique behaviour with regard to mechanical strength, acoustics, lattice dynamics, photonics, electronics, magnetism, dielectrics, and chemical reactivity [2]. In other respects, nitrides of the III-V semiconductor family have recently received widespread attention as electronic material for various applications in photonics [3,4]. When nanostructured, it appears the wide band gap material AlN (6.2 eV in the ground state) can be an adequate host matrix for lanthanides to increase their photoluminescence [5-10]. Although the mechanisms of this phenomenon are not yet fully understood, authors agree that the presence of oxygen atoms seems to play a crucial role [11-13]. It is indeed also known that the introduction of oxygen atoms inside the AlN würztite plays a significant role in its other potentially interesting physical properties. For instance, for oxygen values less than 6 at. \%, different studies show the modification of thermal conductivity $[11,14]$, general optical properties (like optical reflectivity, absorption, refraction indices or cathodo-luminescence [11,19]), piezoelectricity or elastic characteristics $[16,20]$ or electrical resistivity [21,22].

As both the nanostructure and the presence of oxygen in the AlN matrix seem to have effects on the photoluminescence mechanism of rare earths, it is important to clarify the correlation between the two parameters.

Previous studies showed it is possible to obtain a variety of homogeneously nanostructured films by choosing adequate process parameters of a PVD r.f. magnetron deposition system [13]. Amorphous films and nano-granular films with crystallites of different shapes: equiaxed, short rods or columns were obtained. The different nanostructured films were obtained by combining the influences of magnetron power $\mathrm{W}$ and the 
working plasma pressure P [13]. Unfortunately, very low deposition rates were required to synthesise amorphous and nano-structured AlN, consequently contaminating the films by oxygen of the residual pressure.

The present study wishes to explore and understand the influence of oxygen on the nanostructural morphology of AlN films prepared by r.f. magnetron sputtering. This academic work has been performed to decorrelate the influence of oxygen presence inside the films independently of the experimental magnetron sputtering parameters $\mathrm{W}$ and $\mathrm{P}$. To do so, AlN films were synthesized with deliberately high oxygen contaminations beyond the ranges of oxygen concentration acceptable for classical technological use of these kinds of films. This will hopefully allow a better understanding of the modification of their physical properties.

The paper describes the experimental reactive magnetron sputtering set-up specifically designed and assembled for deposition under ultra low residual pressures. The experimental procedure to prepare the films are given . The experimental characterization techniques are detailed. The morphology of the films was studied by Transmission Electron Microscopy (TEM). Chemical compositions were measured by Energy Dispersive X-ray Spectroscopy (EDXS) and Auger Electron Spectroscopy (AES).

\section{Experimental details}

\subsection{Synthesis}

The chosen substrates are [001] oriented silicon wafers. They are cleaned with basic solvents. The last stage of cleaning is an ultrasonic bath in distilled water. The synthesis is performed in a baking UHV (Ultra High Vacuum) chamber using a classical diffusion-pump. It is equipped with a r.f. (13.56 MHz) pulsed magnetron sputtering system especially designed to work under UHV conditions delivering the magnetron power W (50 $<\mathrm{W}<300 \mathrm{~W}$ ). A liquid nitrogen-cooling trap is used to absorb water vapour. The obtained background pressure is around $1.10^{-6} \mathrm{~Pa}$ of $\mathrm{H}_{2} \mathrm{O}$ controlled by mass spectroscopy. In this 
study, polarization of substrate is set to 0 Volt. The target disk is made of pure aluminium (purity of $99.99 \%$ ), its diameter and its thickness are $60 \mathrm{~mm}$ and $3 \mathrm{~mm}$ large respectively and its distance from the sample is set to $150 \mathrm{~mm}$. The target was systematically sputter cleaned for 15 min using an Ar plasma to remove the native oxide contamination (cleaning conditions: $\mathrm{P}=0.5 \mathrm{~Pa}, \mathrm{~W}=300 \mathrm{~W})$. A gas mixture of $\mathrm{Ar}$ and $\mathrm{N}_{2}$ of high purity $(99.999 \%)$ is used for sputtering. The percentage $\alpha$ of $\mathrm{N}_{2} /\left(\mathrm{Ar}+\mathrm{N}_{2}\right)$ in the gas mixture is set to $75 \%$. Three qualities of $\mathrm{N}_{2}$ gas with different ratios of oxygen were used to obtain different oxygen contents in the films. During the treatment, a controlled pumping valve and massflow controllers are used to keep the total sputtering pressure $\mathrm{P}$ constant $(0.2 \mathrm{~Pa}<\mathrm{P}<5$ Pa). The flow rates of argon, nitrogen and oxygen gases are controlled with MKS Mass-Flo Meters (total gas volume $=5 \mathrm{sccm}$ ) and the total working pressure is measured using a MKS Baratron gauge. Prior to deposition, the chamber is set into operation with the chosen plasma conditions for $30 \mathrm{~min}$ so that the reactor can reach its thermal equilibrium. The temperature of the substrate during deposition is measured with a thermocouple. It was found that the temperature changes remained below $330 \mathrm{~K}$. It was concluded that the heating is only due to the plasma heating. The reactor was equipped with an interferential optical reflectometer for real-time control of the thickness and the growth rate of the deposited layer [23]. Six films were prepared. The three first ones were deposited using $\mathrm{W}_{1}$ $=50 \mathrm{~W}, \mathrm{P}_{1}=1,5.10^{2} \mathrm{~Pa}$ and the three qualities of $\mathrm{N}_{2}$ gas. The three other ones were deposited according to the same procedure but using $\mathrm{W}_{2}=200 \mathrm{~W}, \mathrm{P}_{2}=0,5.10^{2} \mathrm{~Pa}$ (preparation conditions are listed in table I).

\subsection{Characterization techniques}

Detailed phase identification and chemical composition were obtained by Transmission Electron Microscopy (TEM - PHILIPS CM20 microscope operating at an accelerating voltage of $200 \mathrm{kV}$ ) equipped with an ultra thin window X-Ray detector to perform EDSX (Energy Dispersive Spectroscopy of X-rays). Samples were prepared using 
the technique of micro cleavage. The homogeneity of each sample was checked: several zones of each film were micro-cleaved and several chicks of matter were studied for each micro-cleavage. The results were found to be reproducible in each case. The chemical analyses were carried out in nanoprobe mode with a probe diameter of $14 \mathrm{~nm}$. The relative precision of these results is $5 \%$. All chemical analyses were then confirmed by Auger spectroscopy. An Auger electron spectrometer (AES) was used to confirm the chemical analyses and to depth profile the elemental distributions of the films (Microlab VG MKII using an Ar etching gun VG microprobe EX05). The sensitivity factors of the two chemical techniques were determined using $\mathrm{AlN}$ and $\mathrm{Al}_{2} \mathrm{O}_{3}$ reference samples.

\section{Results}

Three kinds of samples were obtained: low, middle and very high oxygen content samples as compiled in table I. Films grew on a transitional amorphous layer at the film substrate boundary of few nanometers whose formation can be explained by the reaction between the $\mathrm{SiO}_{2}$ native layer and $\mathrm{AlN}$ [24]. Grazing X-ray diffraction (not shown here) shows the crystallized (nano-columnar, quasi-columnar with defects or made of short rods) films are preferentially [002] oriented and showed that no other peaks than the one of the AlN würztite could be spotted.

Regardless of $(\mathrm{P}, \mathrm{W})$, the films containing less oxygen (5 at. \%) had a nanocolumnar structure (Fig. 1a and c). Columnar grains were straight and were between 10 and $30 \mathrm{~nm}$ in width. They grew accordingly to a classical Van der Drift mechanism [25]. Their diffraction patterns could be indexed using the AlN rings würtzite structure (as shown in Fig. 1d - J.C.P.D.S. file $\left.\mathrm{N}^{\circ} 25-1133\right)$.

The films with middle oxygen content $\left(15\right.$ at. \%) prepared by using $\left(\mathrm{W}_{2}=200 \mathrm{~W}, \mathrm{P}_{2}\right.$ $=0.5 \mathrm{~Pa}$ ) had a quasi-columnar microstructure, made of columns containing a lot of defects (Fig. 2c). The width of the columns was around $10 \mathrm{~nm}$. The diffraction patterns recorded on this film still presents the AlN rings only (Fig. 2d). 
The one prepared by using $\left(\mathrm{W}_{1}=50 \mathrm{~W}, \mathrm{P}_{1}=1.5 \mathrm{~Pa}\right)(30$ at. $\%)$ contained short nano-rods whose widths are around $5 \mathrm{~nm}$ (Fig. 2a). The diffraction pattern of this sample is typical from the one of a polycrystalline material with small grains and the rings are located at the position of the AlN rings (Fig. 2b).

The microstructures of oxygen-rich films (50 at. \%, 55 at. \%), made by using either $\left(\mathrm{W}_{1}, \mathrm{P}_{1}\right)$ or $\left(\mathrm{W}_{2}, \mathrm{P}_{2}\right)$, were found to be amorphous (Fig. 3). TEM diffraction patterns recorded on the samples are made of diffuse rings (Fig. $3 \mathrm{~b}$ and d) and TEM images recorded on the samples are typical of an amorphous phase: they exhibit the typical orange skin contrast (Fig. 3a and c).

Except for the amorphous samples, the electron diffraction patterns of all samples could be indexed using the reflections of the würtzite structure of AlN. To be sure that the sample made with 30 at. \% of oxygen does not exhibit hidden reflections of another phase: a deconvolution of the cumulated radial intensity of the diffraction pattern was performed. Fig. 4 shows the satisfying deconvolution obtained of the most intense ring. Deconvolution was a success in the case of a solution giving three peaks. These peaks were located at the positions of the AlN most intense reflections (100), (002) and (101) and were exhibiting a similar full width at half maximum (Fig. 4a). No fourth signal is necessary. This attests that the AlN sample prepared with 30 at. \% oxygen contains no crystallized AlNO, no amorphous AlNO nor amorphous AlN, and is only made of würtzite AlN. The typical cumulated radial intensity of the diffraction pattern of the amorphous samples prepared with 50,55 at. $\%$ oxygen content (recorded with the same camera length) is juxtaposed to precise the relative locations of the main peaks of AlN and the most intense ring of the amorphous phase. Respective radii are indicated.

\section{Discussion}

The work is dedicated to the effect of oxygen on the nano-structure of AlN deposits prepared at room temperature. To our knowledge, no research study has been devoted specifically to the influence of oxygen and to its consequences on the crystalline structure and to the morphology of the films in aluminium nitride obtained by deposition techniques 
and particularly in AlN prepared by magnetron sputtering. These kind of approaches (influence of oxygen on crystalline structure) are however common in literature within the framework of obtaining monocrystals at high temperatures. These works show that when AlN contains very low oxygen ratios (as impurity or < few atomic 2-3 at. \%), oxygen enters the AlN lattice via a mechanism involving a vacancy creation model, by substituting for nitrogen atoms decreasing the AlN reticular distances, and creating point defects [14, 26-29]. When the oxygen content increases (up to 6 at. \%), it is shown that the aluminum and oxygen atoms form octahedral atomic configurations that become the structural units of planar defects identified as inversion domain boundaries (IDBs) [26-29]. These IDBs are usually planar and lie in the basal $\{001\}$ planes. However they can also be curved as they can exist in the pyramidal $\{101\}$ and prismatic $\{100\}$ planes of the würtzite and create corrugation of the plane by inserting kinks or jogs into the IDB planes [28-31]. At higher oxygen contents $(10 \pm 3$ at. \%), the superimposing of IDBs can lead to polytypoids structures [31-32].

In our study, the samples were prepared by magnetron sputtering at room temperature. As the melting temperature of AlN is very high $(\sim 2500 \mathrm{~K})$, it implies that, once the AlN würtzite has crystallized, surface and volume diffusion of species including oxygen is very limited (one recalls the depositions are performed at room temperature). This behaviour can be deduced from the EELS (Electron Energy-loss oxygen diffusion studies in [33-34]). It also means that the structure and morphology to be observed are the one built as the species arrive on the film according to a "hit and stick" mechanism: oxygen atoms stay on their impact site or at most a few atomic sites away. Within such a context, as it was demonstrated by Xu et al. on AlN films developing either [002] or [100] textures [35], the value of energy (kinetic) of the building species plays a key role on the growth. In our experimental set-up, the kinetic energy of the building species of the AlN film can be modified by different parameters. Firstly, an increase of plasma pressure will reduce this energy (thermalization of building species: mean free path $\sim 10-50 \mathrm{~mm}$ in the 0.5-1.5 Pa pressure range with a target-substrate distance of $15 \mathrm{~mm}$ ). Secondly, a decrease of power, which is in our case due to a simultaneous decrease of voltage and current, will also reduce this energy. As a consequence, the films built using the conditions (W1 $=50$ $\mathrm{W}, \mathrm{P} 1=1.5 \mathrm{~Pa}$ ) were synthesized with species having a lower energy than the one prepared by using the $(\mathrm{W} 2=200 \mathrm{~W}, \mathrm{P} 2=0.5 \mathrm{~Pa})$ conditions, $\mathrm{P} 1>\mathrm{P} 2$ and $\mathrm{W} 2>\mathrm{W} 1$. To summarize, the films of this study have been synthesized with a very limited superficial and volume film diffusion according to two energetic regimes: one low, one high.

These two preliminary discussions allow now the interpretation of the structural characterizations. Firstly, the study presented in this work shows that the polycrystalline 
films (oxygen $<30$ at. \%) contain only the $\mathrm{AlN}$ phase: no alumina $\left(\gamma-\mathrm{Al}_{2} \mathrm{O}_{3}\right.$ spinel) or spinel oxynitride signature could be observed on any diffraction pattern. This technique could however miss the presence of phases if they were present in small proportions. However missing a high proportion of such extra phases would not be consistent with the fact that the contrast of the rings is very net and no extra signal could be spotted. This point was established by means of selected area electron diffraction records by using an aperture allowing the analysis of a $300 \mathrm{~nm}$ zone on many locations of the film and with GIXRD (Grazing Incidence X-ray Diffraction) patterns recorded on samples (not shown here). These observations allow us to conclude that the films are essentially made of würtzite up to 30 oxygen atomic $\%$. Oxygen introduction does not lead to the formation of secondary oxygen rich phases (crystallized $\mathrm{Al}_{2} \mathrm{O}_{3}, \mathrm{AlNO} \ldots$...)

This first result raises the question of the localization of oxygen atoms. The only possible locations are in defects: either at grain boundaries or in volume. The location at the grain boundaries can however be ruled out. Indeed, the films synthesized for this study are prepared at such temperatures that the building mechanism is a "hit and stick" one and that the surface and volume diffusions are very low. Under such conditions, they cannot thus be the special hosts of these atoms. The most probable locations for the oxygen atoms are therefore: throughout the volume of the grains and in crystalline defects. The formation of oxygen rich planar defects by diffusion cannot be envisaged either for the same reasons. One can then suppose that the oxygen presence creates point defects either by substitution as mentioned above in literature either by insertion. The accommodation by substitution is known to create in parallel vacancies (electronic defects). As the oxygen content increases, the density of point defects (vacancies, insertion, substitution) increases. The more the content increases, the more the probability of creating two or multiple adjacent defects increases. One can understand that above a critical size the stacking of hexagonal würtzite lattices is perturbed. This crystallographic disorder provokes interruptions of perfect epitaxial growth of AlN on AlN, this creates germs for grains exhibiting crystallographic directions different from the one underneath: it is a rupture of epitaxy. This consequently creates slightly disoriented grains and creates new grain boundaries. Columns cannot grow correctly and there is growth of smaller grains. Therefore high oxygen concentrations increase the number of grains decreasing their size and increasing so the density of grain boundaries. Observation of TEM images shows that as more oxygen is introduced into the film, the more the grain size decreases.

At high energy, several (many) fringes contrast can be observed in samples: cf. arrows in Fig. 1 where TEM data obtained on sample W2, P2 prepared with $5 \mathrm{O} \%$ is displayed (cf. arrows Fig. 2 sample W2, P2 prepared with $15 \mathrm{O} \%$, respectively). They 
could either be due to disinclinations between two grains thus creating a moiré contrast, but this would not explain why they are not observed in samples prepared with low energy. They might then be due to the presence of stacking faults being able to produce such fringes in AlN: IDBs (well documented in [28-31]). These IDBs are known to be made of octahedral configurations containing oxygen atoms. They could have been created due to the extra available energy of species promoting the creation of a cluster of oxygen atoms in a plane and would be more present when $\mathrm{O}$ atomic \% increases. With low volume diffusion values, such planar defects can only be due to high concentration of oxygen atoms minimizing the thermodynamic energy of the system. Unfortunately, the numerous superimposing of grains exclude the use of the classical two waves $+\mathrm{g} / \mathrm{g}$, bright field, and dark field analysing technique to measure the exact nature of the stacking faults ( $\mathrm{g}$ is the diffraction vector used to build the bright or dark field image) [36]. Further TEM experiments are in progress to disprove or confirm this last hypothesis (High Resolution Electron Microscopy).

At very high oxygen contents, the density of defects becomes extremely high. No AlN phase domain exists. Amorphous diffraction rings appear (Fig. $3 \mathrm{~b}$ and d). It can be attributed to an AlNO amorphous phase, as shown by the chemical analyses $\left(\mathrm{W}_{1}, \mathrm{P}_{1}, 50\right.$ at. $\% \mathrm{O})\left(\mathrm{W}_{2}, \mathrm{P}_{2}, 55\right.$ at. \% $\left.\mathrm{O}\right)$. The position of the first diffraction ring, measured on electron diffraction patterns, is located at $d_{a} \approx 0.30 \mathrm{~nm}$ (Fig. 3b and d Fig. 4c).

This study, dedicated to the role of oxygen in the microstructures of AlN prepared by r.f. magnetron, is consistent with observations by several authors. For instance, in 2005, Liu et al. suggested that AIN crystallization was governed by an absence of oxygen in their chamber due to its consumption during the amorphous layer growth [37]. Earlier, during deposition of AlN/AlNO films, controlled additions of small amounts of oxygen in the feed gas made the X-ray peaks recorded on the films disappear revealing a decrease in their crystallographic order [38]. Our results are also consistent with the observations made by Vergara et al. They noticed that the size of AlN grains in the sputtered AlN films decreased with increasing $\mathrm{O}$ at. \% [20]. The sequence of apparition of phases (würtzite AlN and amorphous AlNO) versus the oxygen content is consistent with Richthofen et al.'s results [39]. Very disturbed würtzite AIN films containing from 7 to 30 oxygen at. \%, with a variable grain size ( 5 to $30 \mathrm{~nm}$ ) and amorphous AlNO at 33.4 oxygen at. \% using magnetron sputtering ion plating with similar process conditions were obtained. The presence of the phases and their evolution (the i.e. sequence of apparition of phases) with increasing oxygen at. $\%$ is consistent with our finding. The domain boundaries of the phases are shifted due to ion bombardment as they imposed a bias voltage of $-25 \mathrm{~V}$. Similarly, the AlN films of Lim et al. containing $20 \% \mathrm{O}$ at. \% (doped with Er and Si) 
presented also a broad X-ray diffraction spectrum suggesting that if the structure is not amorphous, the grain size is sufficiently small to widen all peaks [8].

\section{5 . Conclusions}

The work presented here deals with the strong influence of oxygen on the structure and growth mode of room temperature r.f. magnetron prepared films. After its description one proposes an interpretation on the way oxygen enters the films.

Oxygen seems to enter the AlN würtzite by point defects randomly distributed throughout the volume of the film. Low contents do not perturb the columnar growth of the films, although higher contents lead to a reduction in the grain size. The authors have proposed an explanation based on higher and higher probability of accumulating point defects provoking epitaxy ruptures as the oxygen content increases up to 30 atomic $\%$. For contents above 50 at. \% the structure becomes amorphous thus confirming the hypothesis already quoted that the oxygen presence causes the amorphization of AlN deposits.

It is important to note that even for high contamination by oxygen atoms (5-30 at. $\%$ ), the growth of films of würztite AlN by r.f. magnetron sputtering at room temperature can be made without the formation of crystalline $\mathrm{AlNO}$ or $\mathrm{Al}_{2} \mathrm{O}_{3}$ phases (only traces may be present, amorphous phases may be present but in very small quantities, thus leaving no signature in our diffraction recordings).

By making AlN films deliberately contaminated at different rates of oxygen, this study has proposed an assumption on the location of oxygen in the crystallized AlN nanostructures. This will have to be taken into consideration for the comprehension and interpretation of the physical properties of aluminium nitride nano-crystalline structures, when for example; the compound is purposely doped for optical applications, in the presence of oxygen. Indeed, the localization of oxygen is an important parameter to understand the photoluminescence or rare earths inside matrices like AlN [10,12]. Oxygen concentration is actually demonstrated to have a great effect on the environment of 
luminescent elements and on their activation. Its localization (then also its diffusion, provoked by annealing) is a key parameter to enhance the photoluminescence of rare earths in such big gap matrices.

Acknowledgments: The authors wish to thank J. Ghanbaja and D. Genève for performing the TEM and AES analyses, respectively. 


\section{References}

1. S.C. Tjong, H. Chen, Mater. Sci. \& Eng.: R: Reports, 45, 1-2 (2004) 1a

2. C. Q. Sun, Prog. in Solid State Chem., 35, 1 (2007) 1

3. S. J. Pearton, C. R. Abernathy, F. Ren, R. J. Shul, S. P. Kilcoyne, M. HagerottCrawford, J. C. Zolper, R. G. Wilson, R. G. Schwartz, J. M. Zavada, Mater. Sci. \& Eng. B, 38, 1-2 (1996) 138

4. H. X. Jiang, J. Y. Lin, Critical Rev. in Solid State \& Mater. Sci., 28, 2 (2003) 131

5. R. Weingärtner, O. Erlenbach, A. Winnacker, A. Welte, I. Brauer, H. Mendel, H.P. Strunk, C.T.M. Ribeiro, A.R. Zanatta, Optic. Mater., 28, 6-7 (2006) 790

6. J.-W. Lim, W. Takayama, Y.F. Zhu, J.W. Bae, J.F. Wang, S.Y. Ji, K. Mimura, J.H. Yoo, M. Isshiki, Curr. Appl. Phys., 7, (2007) 236

7. S. B. Aldabergenova, M. Albrecht, H. P. Strunk, J. Viner, P. C. Taylor, A. A. Andreev, Mat. Sci. \& Eng. B 81 (1-3) (2001) 144

8. K. Gurumurugan, Appl. Phys. Lett., 74(20), (1999), 3008

9. A.R. Zanatta, Appl. Phys. Lett., 82(9), (2003) 1395

10. V.I. Dimitrova, P.G. Van Pattern, Appl. Surf. Science, 175/176, (2001), 480

11. M.L. Caldwell, P.G. Patten, M.E. Kordesh, H.H. Richardson, MRS Internet J. Nitride Semicond. Res. 6, (2001) 13

12. G.A. Slack, L.J. Schowalter, D.Morelli, J.A. Freitas Jr., J. Cryst. Growth, 246 (2002) 287

13. J.C. Oliveira, A. Cavaleiro, M.T. Vieira, L. Bigot, C. Garapon, B. Jacquier, J. Mugnier, Optic. Mater., 24 (2003) 321

14. V. Brien, P. Pigeat, J. Cryst. Growth, 299 (2007) 189

15. G.A. Slack, J. Phys. Chem. Solids, 34 (1973) 321

16. R.A. Yougman, J.H. Harris, J. Am. Ceram. Soc., 73, 11 (1990) 3228

17. M. Kazan, B. Bufflé, Ch. Zhheib, P. Masri, J. Appl. Phys., 98 (2005) 103529-1 
18. M. Kazan, B. Bufflé, Ch. Zgheib, P. Masri, Diam. Rel. Mater., 15 (2006) 1525

19. M. Bickerman, B.M. Epelbaum, A. Winnacker, Phys. Stat. Sol., 7(2003) 1993

20. W. Dehuang, G. Liang, Thin Solid Films, 198 (1991) 207

21. L. Vergara, M. Clement, E. Iborra, A. Sanz-Hervas, J. Garcia Lopez, Y. Morilla, J. Sandragor, M.A. Respaldiza, Diam. Rel. Mater., 13 (2004) 839

22. O. Elmazria, M.B. Assouar, P. Renard, P. Alnot, Phys. Stat. Sol. A, 196, 2 (2003) 416

23. R.W. Francis, W.L. Worell, J. Electrochem. Soc., 123 (1976) 430

24. T. Easwarakhantan, M.B. Assouar, P. Pigeat, P. Alnot, J. Appl. Phys., 98, 073531$1073(2005) 531$

25. J.H. Choi, J.Y. Lee, J.H. Kim, Thin Solid Films, 384, (2001) 166

26. A. van der Drift, Philips. Res. Rep. 22 (1967) 267

27. J.H. Harris, R.A. Yougman, R.G. Teller, J. Mater. Res., 5, 8 (1990) 1763

28. A.D. Westwood, M.R. Notis, J. Am. Ceram. Soc., 74, 6 (1991) 1226

29. A. Berger, J. Am. Ceram. Soc., 74, 5 (1991) 1148

30. A.D. Westwood, R.A. Youngman, M.R. McCartney, A. N Cormack, M.R. Notis, J. Mater. Res., 10, 5 part I (1995) 1270

31. A.D. Westwood, R.A. Youngman, M.R. McCartney, A. N Cormack, M.R. Notis, J. Mater. Res., 10, 5 part II (1995) 1287

32. A.D. Westwood, R.A. Youngman, M.R. McCartney, A. N Cormack, M.R. Notis, J. Mater. Res., 10, 5part III (1995) 2573

33. G. Van Tendeloo, K.T. Faber, G. Thomas, J. Mater. Sci., 18 (1983) 525

34. M. Sternitzke, G. Müller, J. Amer. Ceram. Soc. (77) 3 737-742 (1994)

35. H. Solmon, D. Robinson, R. Dieckmann, J. Amer. Ceram. Soc. (11) 2841-48 (1994)

36. X.H. Xu, H.S. Wu, C.J. Zhang, Z.H. Jin, Thin Solid Films 388 (2001) 62 
37. D.B Williams, C.B Carter, Transmission Electron Microscopy, A textbook for materials science, Plenum press, New York (1996) 387

38. W.-J. Liu, S.-J. Wu, C-M Chen, Y.-C. Lai, C.-H. Chuang, J. Cryst. Growth 276 (2005) 525

39. N.J. Ianno, H. Enshaby, R.O. Dillon, Surf. Coat. \& Tech., 155 (2002) 130

40. A. Van Richthofen, R. Domnick, Thin Solid Films, 283, (1996) 37

List of Figure and table captions

Fig. 1: TEM characterization of the poorest samples in oxygen (5 at. \%). a/ and c/ are TEM bright field images. b/ and d/ are TEM selected area electron diffraction patterns. $\mathrm{a} /$ and $\mathrm{b} /$ Sample prepared using $\left(\mathrm{W}_{1}, \mathrm{P}_{1}\right)$. c/ and d/ Sample prepared using $\left(\mathrm{W}_{2}, \mathrm{P}_{2}\right)$. Indexation of würtzite AlN is mentioned in $\mathrm{d} /$.

Fig. 2: TEM characterization of the samples containing between 15 and 30 at. $\%$ of oxygen. a/ and c/ are TEM bright field images. b/ and d/ are TEM selected area electron diffraction patterns recorded by using the $300 \mathrm{~nm}$ diameter aperture. a/ and b/ Sample prepared using $\left(\mathrm{W}_{1}, \mathrm{P}_{1}\right)$ containing 30 at. \%. c/ and d/ Sample prepared using $\left(\mathrm{W}_{2}, \mathrm{P}_{2}\right)$ containing 15 at. $\%$.

Fig. 3: TEM characterization of the richest samples in oxygen (50, 55 at. \% O ). a/ and c/ are TEM bright field images. b/ and d/ are TEM selected area electron diffraction patterns recorded by using the $300 \mathrm{~nm}$ diameter aperture. a/ and b/ Sample prepared using $\left(\mathrm{W}_{1}, \mathrm{P}_{1}\right)$. c/ and d/ Sample prepared using $\left(\mathrm{W}_{2}, \mathrm{P}_{2}\right)$. 
Fig. 4: a/ Cumulated radial intensity of diffraction pattern of Fig. 2d. I is the average intensity over circles. Top graph is the satisfying deconvolution with the main AlN peaks b/ Cumulated radial intensity of diffraction pattern of Fig. 3b.

Fig. 5: TEM micrographs showing the typical fringes contrast found a/ in sample $\left(\mathrm{W}_{2}, \mathrm{P}_{2}\right.$, 5 at. $\% \mathrm{O}) \mathrm{b} / \mathrm{c} /$ and $\mathrm{d} /$ in sample $\left(\mathrm{W}_{2}, \mathrm{P}_{2}, 15\right.$ at. \% $\left.\mathrm{O}\right)$.

Table I: Oxygen content (atomic \%) measured by EDSX (confirmed by AES) in the films prepared for this study. The probe was focused in the middle of the cross sections of the films. General process conditions are indicated. 

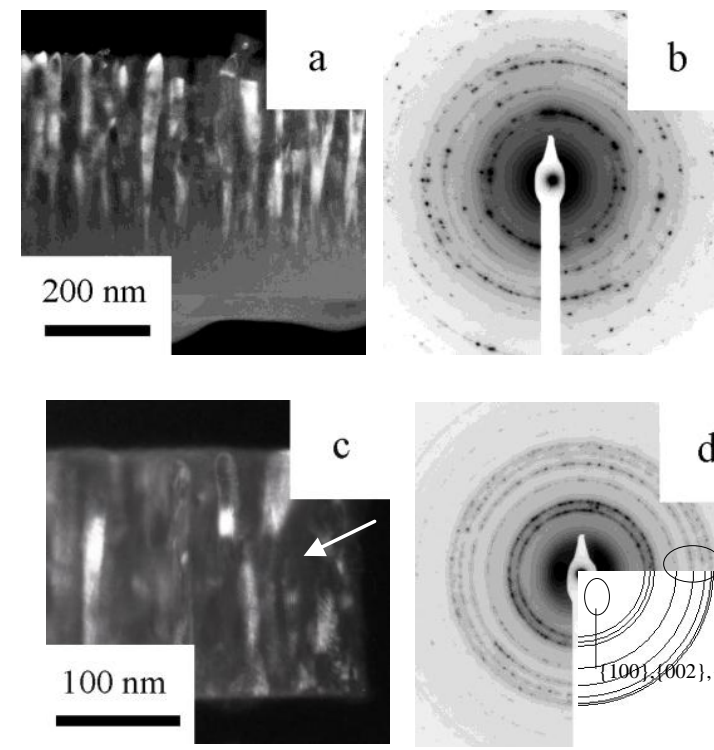

d

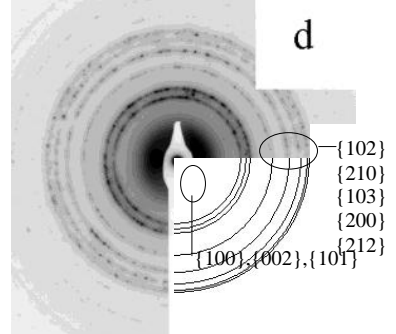

Figure 1 

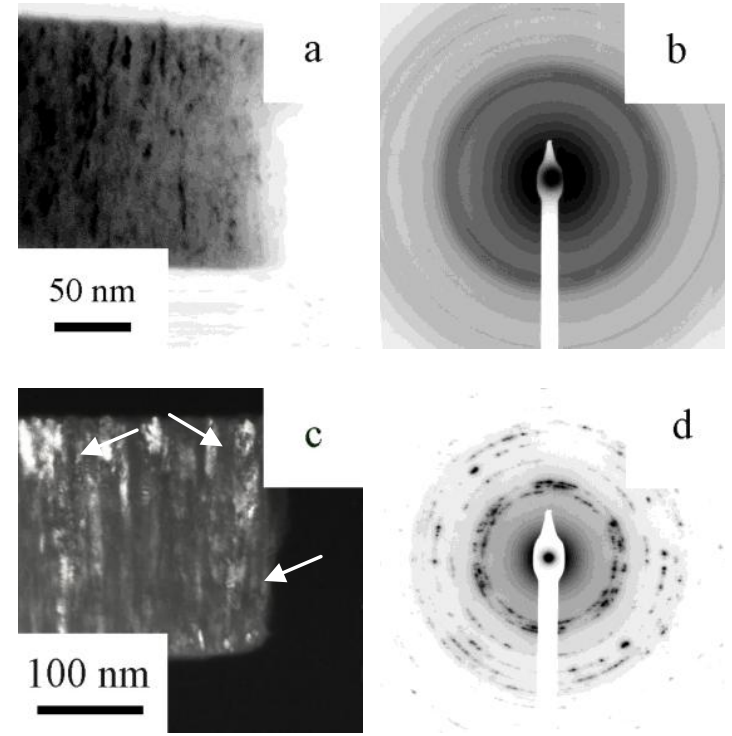

d

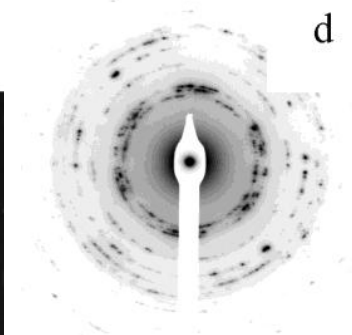

Figure 2 


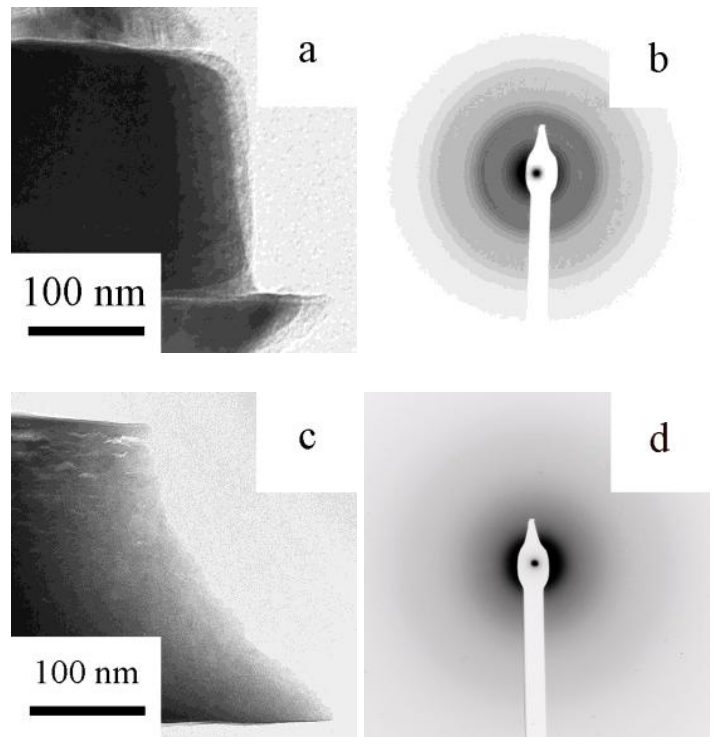

Figure 3 

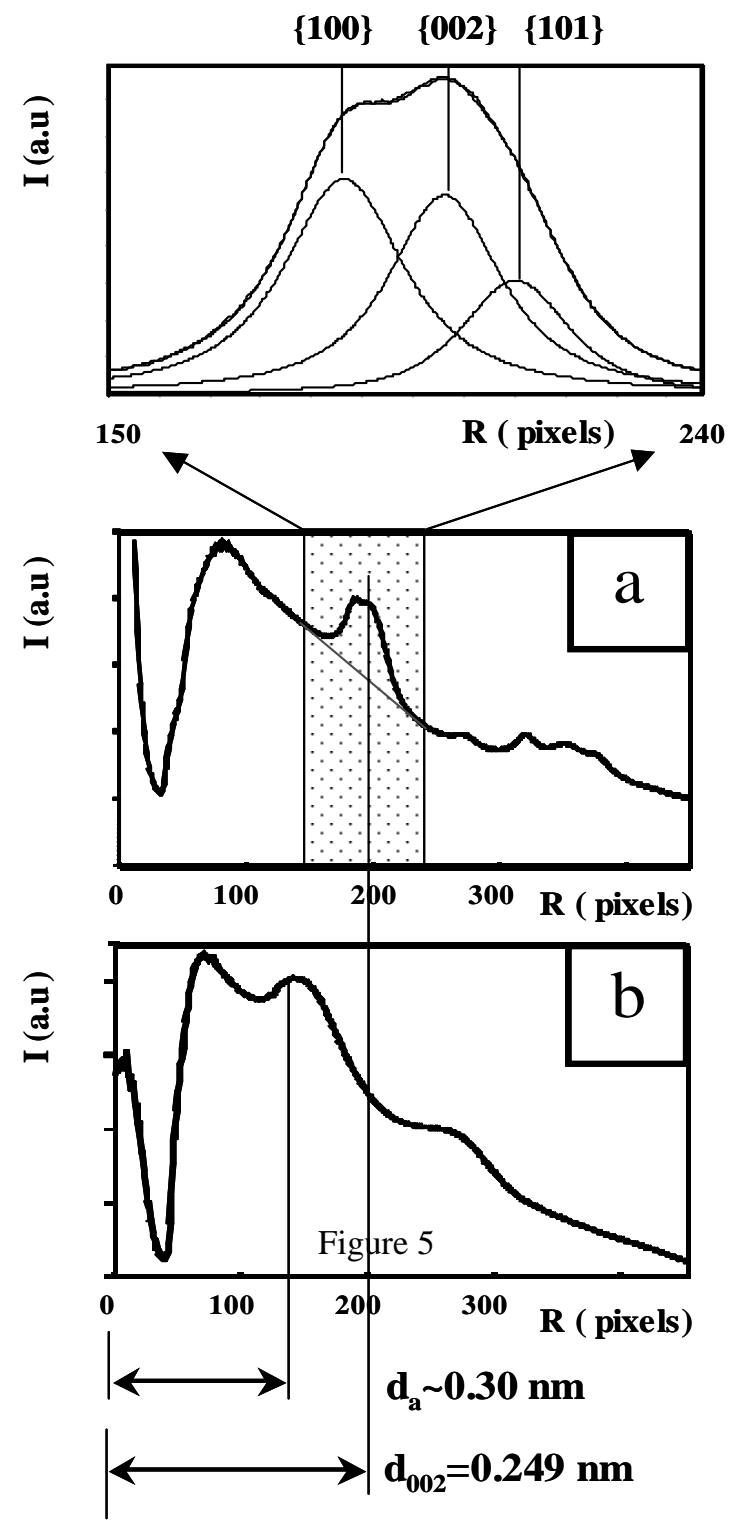

Figure 4 


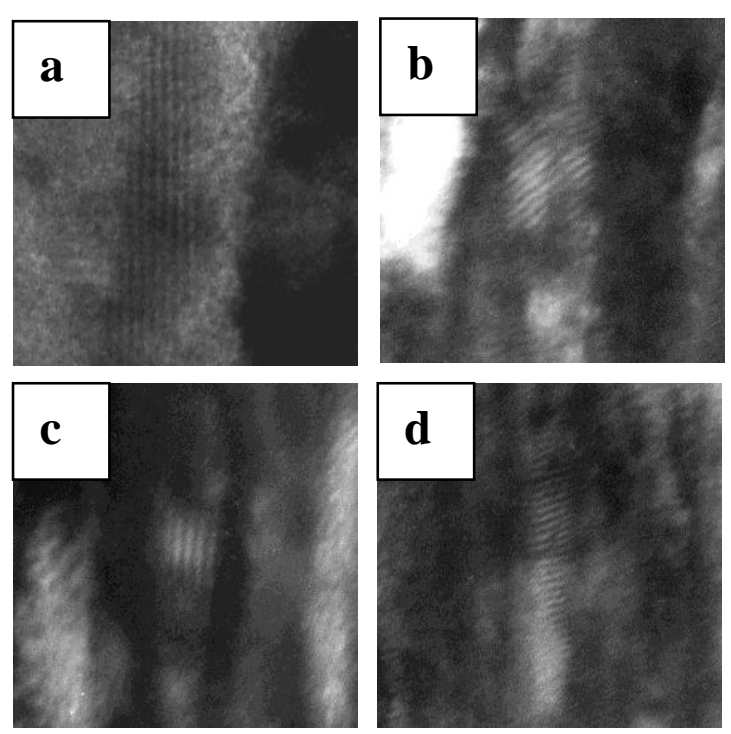

Figure 5 
Table 1

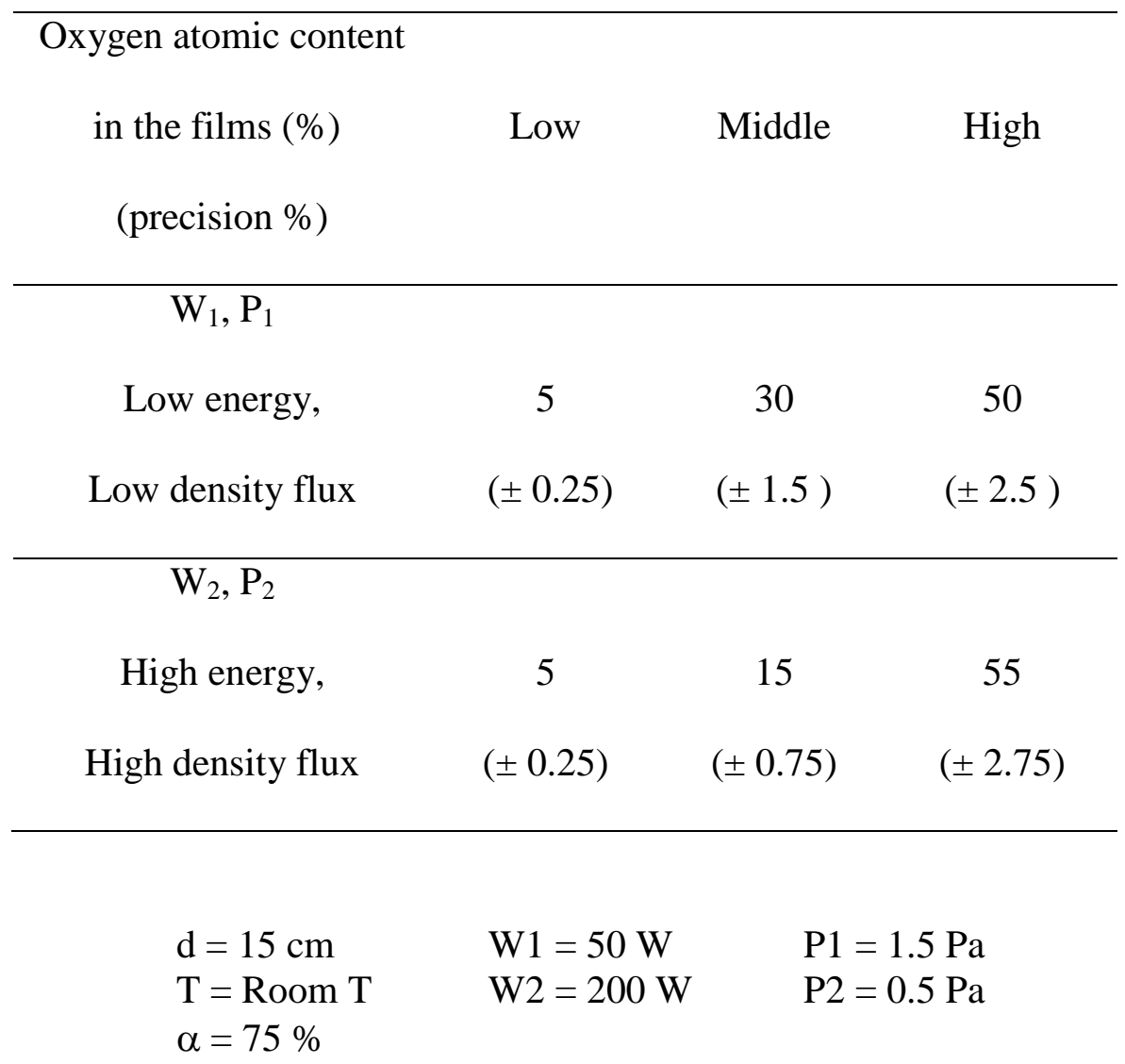

